Zhang, L., Cheng, J., Lei, J.\& Wang, Q.(2020). How the Anonymous Feature of Audience Response System Influences the Interactions of Students by Different Types of Questions. Journal of Educational Technology Development and Exchange, 13(1), 39-56

\title{
How the Anonymous Feature of Audience Response System Influences the Interactions of Students by Different Types of Questions
}

\author{
Lili Zhang \\ Syracuse University \\ Jiaming Cheng \\ Texas Tech University \\ Jing Lei \\ Syracuse University \\ Qiu Wang \\ Syracuse University
}

\begin{abstract}
The Audience Response System (ARS) has been found effective among educators as a good way of using technology to increase participation, involvement, and engagement. Many researchers suggest that the benefits of ARS on students' participation and interactions are associated with its anonymity. ARS questions and using questing strategies during an ARSbased learning activity are also regarded as crucial factors influencing the effectiveness of the implementation of ARS in a class. To examine the influences of the anonymous feature of ARS on students' interactions in light of different types of questions, a post-test only quasi-experiment was conducted with 17 college students. Findings suggested that in a face-to-face class, when given the option, the anonymous feature of ARS was increasingly used by students in their interactions, and the average class interaction was improved. Meanwhile, the effect of the anonymous feature of ARS on students' interactions in class differed according to the types of questions. The anonymous feature might be more useful and effective when students interact with Evaluate questions. While for Create or Apply questions, students preferred real name interactions. Implications for future research were provided for effectively using ARS to facilitate learning.
\end{abstract}

Keywords: Online Learner, Achievement attribution, Performance, Online learning environment, Mediate, Mediating variable, Direct effect, Indirect effect 


\section{Introduction}

\subsection{Audience Response System benefits} learning

In the past decade, the use of Audience Response System (ARS) has been foun effective among educators as a good way to increase student participation, engagement and learning (e.g., Boscardin \& Penuel, 2012; Caldwell, 2007; Draper \& Brown, 2004; Han \& Finkelstein, 2013; Han, 2014; Kay \& LeSage, 2009; Stuart, Brown, \& Draper, 2004 Uhari, Renko, \& Soini, 2003).

ARS is labeled in research literature ARS is labeled in research hiterature (ans persons systens, aud personal response system, classroom response system, electronic feedback system, electronic voting system, immediate response systems, classroom communication systems, an classroom performance system (Hunsu, Adesope \& Bayly, 2016; Kay \& LeSage, 2009). In general, ARS is used to describe echnologies that permit students to answer lectronically displayed questions using a remote-control device, a presentation program remote-control device, a presentation program on laptops, or an application on smartphones, which allows instructors to gather students synchronous responses during a lecture.

ARS has been advanced as a tool to facilitate formative assessment (Boscardin \& Penuel, 2012). Formative assessment is use to monitor students' ongoing understanding of concepts, identify misconceptions, and adjust the course of classroom instruction (Black Wiliam, xtensive evidence suggests that using an ARS helps provide effective formative assessment (Beatty, 2004; Caldwell, 2007; Draper \& Brown, 2004; Simpson \& Oliver, 2007; Stuar et al., 2004). Regular use of an ARS can offer real-time feedback to both instructors and students as to how well concepts are being understood (Kay \& LeSage, 2009). Evaluating the efficacy of ARS thus should not only look at how the ARS influences students' participation and interaction, but also how it supports formative assessment

First introduced in the 1960s, ARS has ignificantly evolved in terms of forms, significantly evolved capabilities, and availabilities from what it used to be - a hardware-software polling system that uses dedicated handheld devicesto more recent mobile-based applications and a host of internet-based platforms, resulting in increasing web-based ARS options, such as offering classroom response functions that reach beyond student polling (Hunsu et al. 2016). Thus, besides multiple-choice questions that many previous studies used in the most cure fur ons is needed, the most current options is needed, such as open-ended questions, multimedia responses, upvoting or downvoting responses, and rank order questions (e.g., Poll Everywhere).

\subsection{The Questions in ARS}

ARS questions and using questing strategies during an ARS-based learning activity are regarded by many researchers as crucial factors influencing the effectiveness of the implementation of ARS in a class (Caldwell, 2007; Hunsu et al., 2016). For instance, researchers suggest that instructors should commit to encouraging pee discussion, creatively facilitating thoughtful discussions, and providing constructive discussions, and providing constive and timely feedback (Husu et al, 2016). Instrectors should also plan discussion time to respond to ARS answers, adapt lesson plans according to the results collected and encourage class discussion of incorrect answers to reveal unclear wording (Caldwell, 2007). Many attempts have also been made to help instructors to develop better questions in order to implement ARS in class more effectively, such as posing tactics to create and adapt suitable questions, aligning questions with pedagogic objectives that can range from checking for und eliciting discussion for conceptur and understanding (Beaty et al, 2006), or combining differt (Beatty et al., 2006), or combining different types of questions to deliver the optimal utilization of ARS (Boscardin \& Penuel, 2012). Therefore, it is necessary and meaningful to investigate how different types of ARS questions influence students' participation and interactions.

\subsection{The Influence of Anonymity}

Many researchers suggest that the benefits of ARS on students' participation and interactions are associated with its anonymity (Kay \& LeSage, 2009), which student have been found to clearly appreciate (Barr, 2017; Caldwell, 2007; Draper \& Brown, 2004; Simpson \& Oliver, 2007; Stuart 1., 2004). Studies in Computer-Mediated Communication (CMC) have suggested that persons in the anonymous condition exhibit disinhibited behavior compared to the identifiable condition (Lapidot-Lefler \& Barak, 2012). Since anonymity removes interpersonal cues, freeing people from the constraining power of social norms or social pressures (Jessup, Connolly, \& Gallagher, 1990), the anonymous CMC provides them with a anonymous CMC provides then with a safe place to express themselves without embarrassment and uneasiness (Yu \& Liu, 2009). Similarly, ARS with the anonymous feature creates a secure environment for learners to respond to instructor's questions without fear or concerns of embarrassment
(Boscardin \& Penuel, 2012), being wrong or being judged (Barr, 2017; Caldwell, 2007; Coleman, Paternite, \& Sherman, 1999; Zhao, 1996), or being singled out (Boscardin \& Penuel, 2012), thus reducing (peer) pressure and anxiety (Barr, 2017; Kay \& LeSage, 2009) associated with answering questions in class.

However, despite the abovementioned positive influences, inadequate studies have been done to investigate the mechanism underneath the implementation of anonymity, especially in light of different types of questions or topics. Writing good ARS questions can be both a demanding and time-consuming task for instructors (Kay \& LeSage, 2009). Knowing what kinds of cont be best in what ARS questions could be best used in what Ans questions can help many practitoners to make informed decision to balance the workload of integration of technology and the effective implementation of instruction.

\subsection{Research Questions}

We attempted to examine the influences of applying anonymous feature of ARS in light of different types of questions in order to provide a more accurate and comprehensive understanding of the influence of anonymity and question types on students' interaction. Thus, this study proposed the following research questions:

(1) How does the anonymous feature of ARS influence students' interactions in a faceto-face class?

(2) How does the type of questions (2) He influence of the anonymous feature of ARS on students' interactions in a face-to-face class?

(3) What are students' opinions, attitudes, 
and satisfaction regarding the use of ARS and its anonymous feature?

\section{Design and Methods}

\subsection{Participants and research context}

A post-test only quasi-experiment was conducted in a northeastern university in the U.S. The participants were 17 preservice teachers ( 2 males and 15 females) who were all seniors. The average age was 21. All participants were recruited from two sections of a 6-week required undergraduate level technology integration course that was concurrently taught by the same instructors. All the students agreed to participate in this study. The participants were all U.S. citizens, English native speakers, and had limited teaching experience with technologies during their field placement in their third year in college.

Researchers suggest that the class size might influence the effectiveness of ARS on students' interactions in class (Han, 2014 Hunsu et al., 2016). The potential benefits associated with the use of ARS diminish as class size increased beyond 50 students, especially for effect on students' engagement, because managing peer discussions and providing constructive feedback would become increasingly challenging for instructors (Hunsu et al., 2016). Thus, the small size class in the current study enabled the instructor to have sufficient time to provide feedback to students' interactions.

The course was the third course in a series of technology integration courses that provided students with the knowledge, skills, and experiences that PreK-12 teachers need in order to incorporate emerging informational and communication technologies into their teaching in the Digital/Information Age. This course placed emphasis on encouraging students to actively interact with each other to share their products, designs, and critical theol settings.

\subsection{Environment and technology}

The course was conducted in a compute b, with one SmartBoard, one projector, and 4 iMacs. Efforts were made before each class to ensure all the students could successfully access digital technology resources through each iMac in the lab. The ARS used in this research was Padlet, an online bulletin board media posts or make comments. Students could also choose whether to use their real name or be anonymous when responding. Padlet is an online digital canvas for collaboration and is not typically used as an ARS. In this study, Padlet enabled students to respond to an instructor-posed question on the digital board and showed the responses to all students simultaneously. In this way, Padlet in this study could be considered as an application of an ARS. Compared to other ARS technologies, Padlet allowed students to post multimedia responses, such as images, hyperlinks, and videos, which provided more possibilities for open-ended questions. open-ended questions. Stents cold also rate and vote on others responses. Meanwhile, unlike most ARS technologies that are mostly used in class in real-time only, Padlet discussion boards in this study were also available to students after class. A screenshot of Padlet used in this study is shown in Figure1.

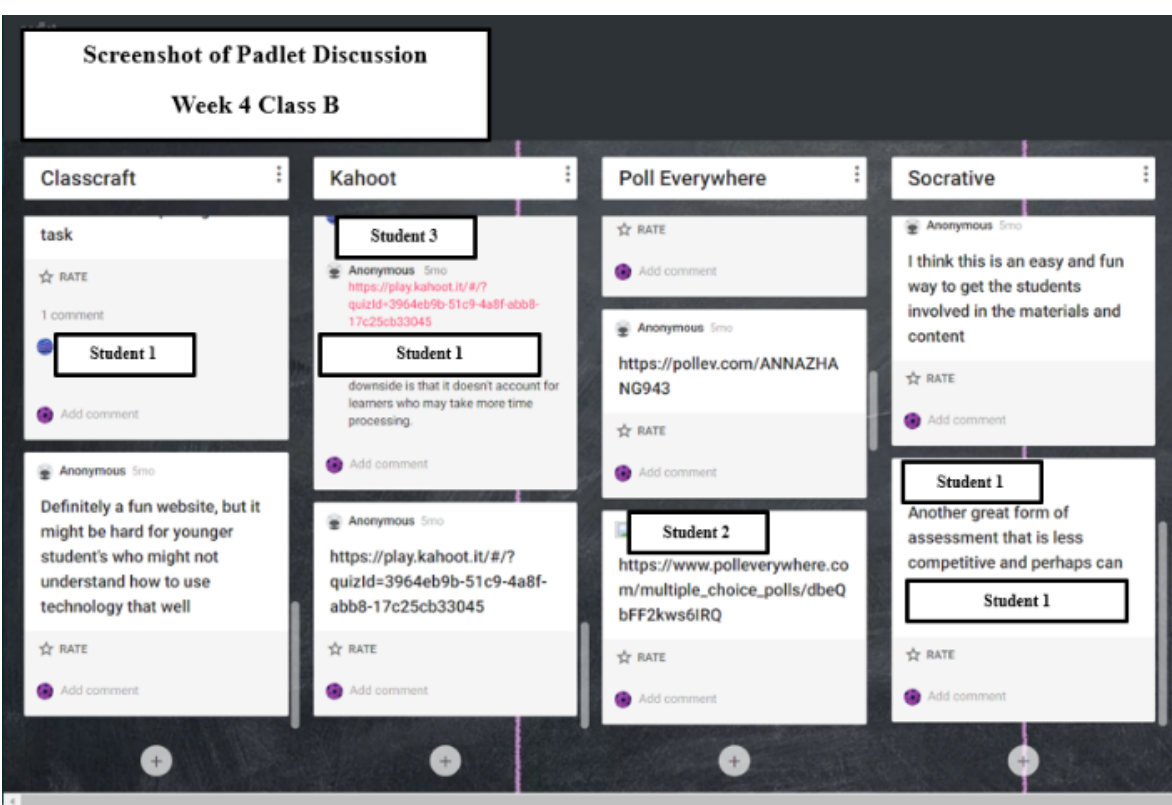

Figure 1. The screenshot of students' interaction in Padlet

\subsection{Procedure}

This experiment started in January 2018 and ended in May 2018. The two sections were randomly assigned into two conditions of treatments: participants in Section A (contro group, $N=9$ ) were asked to provide their real names in Padlet, while participants in Section $\mathrm{B}$ (experiment group, $\mathrm{N}=8$ ) were informed that they could choose to use their real names or be anonymous in Padlet.

A post-survey was conducted at the end of the semester, which contained 1 ) demographic questions and 2) questions regarding students' overall experience, their attitude and satisfaction of the use of Padlet, and their perception of the effectiveness of the anonymous feature, in the formats of both Likert Scale multiple-choice questions an open-ended questions.

\subsection{Instructional strategy}

Many studies reveal that pedagogical factors greatly influence the effectiveness of using ARS in the classrooms (Boscardin \& Penuel, 2012; Han \& Finkelstein, 2013). Thus, in this study, when facilitating the ARS discussion, the instructors followed a set of rules that was designed beforehand to ensure the pedagogy used for the two sections was the same as well as to maintain the anonymity the same as well as to maintain the anonymity
in the experiment group.

The instructors applied the same instructional strategies in the two sections and assigned the same amount of time for students to post their responses to each topic or question. During the two-hour and 15-minute lecture, at least two major discussions were organized at around 20-30-minute intervals. Each lasted for about 15 to 20 minutes. As 
many studies confirmed, when presenting ARS questions at 20-minute intervals, college students are more attentive in the learning process (e.g., Caldwell, 2007; Kay \& LeSage, 2009).

When students participated in the Padlet discussion board, instructors did not walk around or stand behind the participants while they were ty ey were typing. Instructors presented the discussion board on the Smartboard scree and the projector screen. When most student finished typing, or the time for discussion was up, the instructors started to debrief on the discussion by browsing all the responses, then randomly selected several responses to provide feedback. According to Hattie and Timperley (2007), feedback about the elf as a person is the least effective, while seff as a peron is the least effective, while feedback about the task, self-regulation, an he processing of the task are more powerful. In this study, instructors mostly provided feedback about the task and processing of the task, and avoided providing feedback about an individual student, such as "Jason, you did a good job!". This is another way to ensure the anonymity of participants in the experimental group. Instructors avoided asking question that would potentially reveal participants" answer?" Instead, the instructor provided feedback to students in general, such as: "one student pointed out a very good strategy..." or, "this idea is thoughtful, because..." The instructor encouraged oral discussion in addition to the Padlet discussion, such want to comment on this opinion?"

\subsection{Measurement}

The 20 questions used in the course were coded in terms of Bloom's Taxonomy (Remember $=0$, Understand $=1$, Apply $=$ 2 , Analyze $=3$, Evaluate $=4$, Create $=5$ ) Two raters coded the questions individually with initial Kappa values of 0.68. According to Cohen (1960), this reflected a substantial agreement. Then the coders discussed the differences in differences in coding results together, solved the disagreements and recoded, until achieving $100 \%$ agreement.

The count of participants' interactions in Padlet was automatically recorded as scale data. However, as Padlet did not allow us to trace back the author of each anonymous post, we further asked students to retrospectively report in the post-test survey how frequently they interacted in Padlet anonymously (Always $=4$, Most of the time $=3$, About half the time

Students' satisfaction of the use of Padlet in class has seven levels (Very Dissatisfied $=1$; Dissatisfied=2; Sovewhat Dissatisfied = 3 ; Neutral - 4; Somewhat Satisfed = 5; Satisfied $=6$; Very Satisfied $=7$ ). The responses to the question "How effective is the anonymous feature of Padlet in allowing you to interact with others?" has five levels (Extremely effective $=1$; Very effective $=2$; Moderately effective $=3$; Slightly effective $=4$; Not effective at all $=5$ ).

\subsection{Data analysis}

Descriptive analysis was conducted to reveal the patterns and changes in interaction. Chi-square test and Mann-Whitney test were conducted to investigate whether the anonymous feature of ARS influenced students' interactions in face-to-face clas and whether the types of questions differed in identified or anonymous conditions. A t-test was conducted to investigate the difference in satisfaction between two sections. Correlation analysis was used to investigate whethe students' behaviors with ARS were related student behaviors with ARS were related to their satisfaction. Content analysis was explore the patterns of students responses.

\section{Findings}

\subsection{Influence of anonymity}

As shown in Figure 2, according to the data collected, the distribution of students' interactions of all participants from two sections was slightly skewed, with a skewness of 1.03 and kurtosis of 1.81. A Chi-square test was conducted comparing the sections and weeks. Results revealed a significant

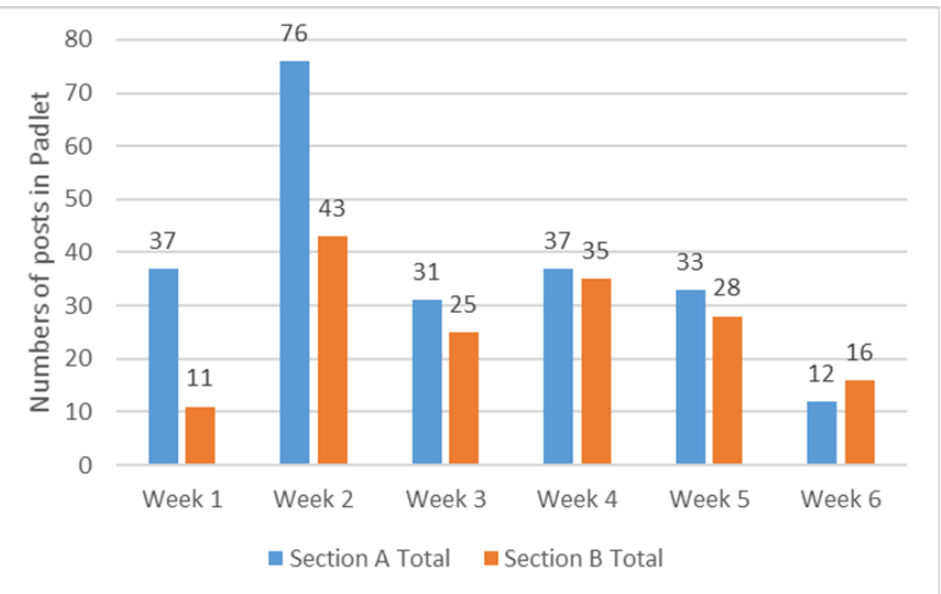

Figure 2. Students' interaction among two sections throughout the six weeks

Table 1. Crosstabulation of students' interactions among two sections by weeks

\begin{tabular}{ccccccc}
\hline \multirow{2}{*}{ Section } & Week 1 & Week 2 & Week 3 & Week 4 & Week 5 & Week 6 \\
\cline { 2 - 7 } A & 37 & 76 & 31 & 37 & 33 & 12 \\
& $(2.7)$ & $(1.3)$ & $(-.6)$ & $(-1.4)$ & $(-.8)$ & $(-1.8)$ \\
B & 11 & 43 & 25 & 35 & 28 & 16 \\
& $(-2.7)$ & $(-1.3)$ & $(.6)$ & $(1.4)$ & $(.8)$ & $(1.8)$ \\
\hline
\end{tabular}

Note. Adjusted residuals appear in parentheses below observed frequencies. Adjusted Residual which had an absolute value greater than two would be deemed significant, less than two would be insignificant. 
Figure 3 shows the number of the identified or anonymous interactions of students in Section B in 6 weeks. Altogethe there were 49 identified posts and 109 anonymous posts. In the first week, none of the students in Section $B$ participated in ef the students in Section B participated in we the any increasing week, the anonymous feature was increasingly used by students in their participation. All the students in Section B interacted with rea names at least once. Two students poste comments with real names frequently $\left(\mathrm{N}_{\mathrm{S} 1}\right.$ $=14 ; \mathrm{N}_{\mathrm{S} 17}=13$ ), while two students never posted with real names after the first week (S14 \& S20). Because the distribution of students' posts was nonparametric, a Mann-Whitney test pas con wo was cond cted to ince average interaction in anonymous condition was significantly higher than that in real name conditions across six weeks. Results showed that students in Section B posted twice as many posts in anonymous conditions than in identified conditions, although the difference

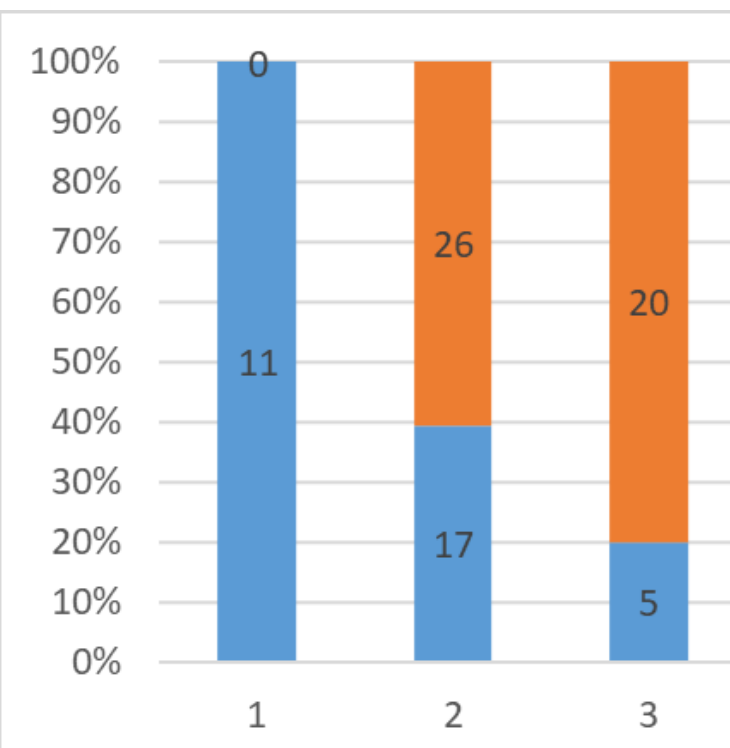

- Section B Real Name

was not statistically significant $(\mathrm{U}=7, \mathrm{p}=$ 0.093). The median number of posts was 8.33 in anonymous conditions compared to 4.67 in real-name conditions.

As for the post-test survey regarding students' self-reported frequency of anonymous interaction in Padlet, among the seven students who answered the the seven students who answered the question, only one reported "never interacted anonymously," and the rest of the student interacted anonymously sometimes $(\mathrm{N}=3)$, most of the time $(\mathrm{N}=2)$ or always $(\mathrm{N}=1)$.

In summary, the findings suggested that the anonymous feature was increasingly used by students when they were given an option to do so. Although students in the identified condition interacted significantly more in he Padlet than students in the anonymous co Padlet than students in the anonymous eek, the difference iminished and became insignificant in the remaining weeks.

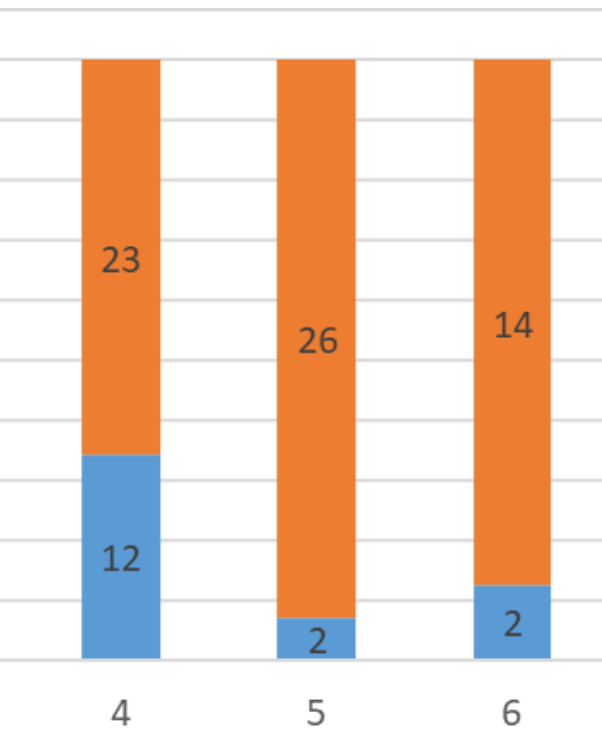

Figure 3. The Number and percentage of real name or anonymous interactions in Section $\mathrm{B}$ in the six weeks
3.2. Interaction of the type of questions and anonymity

Based on Bloom's Revised Taxonomy, five types of questions were asked: remember, apply, analyze, evaluate, and create. The majority $(65 \%)$ of questions fell into the

"Evaluate" category $(\mathrm{N}=13)$, and there were no questions that belonged to the Understand category, which might restrict the power of analysis. Meanwhile, questions that include more than one level questions that include more the sample questions asked for each category.

Table 2. Examples of five types of questions asked based on bloom's revised taxonomy

\begin{tabular}{|c|c|c|}
\hline Types & \multicolumn{2}{|l|}{ Question items } \\
\hline & \multicolumn{2}{|c|}{ Share one example of technology integration during your placement. } \\
\hline Apply & \multicolumn{2}{|c|}{$\begin{array}{l}\text { Based on your own experience, do you agree with the author or not } \\
\text { Why? Give an example? }\end{array}$} \\
\hline Analyze & \multicolumn{2}{|c|}{ What did you learn from others' micro-teaching? } \\
\hline Evaluate & \multicolumn{2}{|c|}{$\begin{array}{l}\text { Please rate this tool and write a review about its strength, areas o } \\
\text { improvement and accessibility, and alternative products. }\end{array}$} \\
\hline Create & \multicolumn{2}{|c|}{$\begin{array}{l}\text { How could you use this tool in your classroom to facilitate you } \\
\text { students' learning? Brainstorm a learning activity that students car } \\
\text { learn with this tool. }\end{array}$} \\
\hline \multicolumn{2}{|c|}{$\begin{array}{l}\text { A Chi-Square test was performed to } \\
\text { investigate the relationship between the type } \\
\text { of questions and students" interactions in two } \\
\text { sections. None of the cells }(.0 \%) \text { have expected } \\
\text { count less than five. The minimum expected } \\
\text { count is } 6.99 \text {. Thus, Pearson's Chi-square } \\
\text { was regarded as appropriate to use. Results } \\
\text { revealed a highly significant relationship } \\
\text { between these two variables }(\chi 2(4, \mathrm{~N}= \\
384)=17.33, p<.01 \text {; Cramer's } V=.21) \text {. As } \\
\text { shown in Table } 3 \text {, for questions regarding } \\
\text { "Apply" and "Create," students' interactions } \\
\text { in Section A were observed significantly more } \\
\text { than expected while those in Section B were }\end{array}$} & $\begin{array}{l}\text { observed significantly less than expected } \\
\text { for questions regarding "Evaluate," students } \\
\text { interactions in Section B were observec } \\
\text { significantly more than expected while thos } \\
\text { in Section A were observed significantly } \\
\text { less than expected. Together they showec } \\
\text { that despite the overall association betweer } \\
\text { sections and the type of questions, student } \\
\text { in Section A were significantly more likely tc } \\
\text { interact with questions regarding "Apply" anc } \\
\text { "Create." In contrast, students in Section } \\
\text { were significantly more likely to interact witl } \\
\text { questions regarding "Evaluate." }\end{array}$ \\
\hline
\end{tabular}


Table 3. Crosstabulation of students' Interactions among two sections by types of questions

\begin{tabular}{cccccc}
\hline & \multicolumn{5}{c}{ Types of Questions (Bloom Taxonomy) } \\
\cline { 2 - 6 } Section & Remember & Apply & Analyze & Evaluate & Create \\
A & 12 & 14 & 12 & 115 & 73 \\
& $(-1.8)$ & $(2.0)$ & $(-.7)$ & $(-2.4)$ & $(3.2)$ \\
B & 16 & 3 & 11 & 100 & 28 \\
& $(1.8)$ & $(-2.0)$ & $(.7)$ & $(2.4)$ & $(-3.2)$ \\
\hline
\end{tabular}

Note. Adjusted residuals appear in parentheses below observed frequencies. Adjusted Residual which had an absolute value greater than two would be deemed significant, less than two would be insignificant.

Similarly, as shown in Table 4, consistent Together, it indicated that students were with the results between two sections, in more likely to interact with "Create" or Section B, students responded to "Evaluate" "Apply" questions in real name condition and questions anonymously much more than using respond to "Evaluate" questions anonymously. real names.

Table 4. Crosstabulation of students' interactions in Section B among two conditions by types of questions

Types of Questions (Bloom Taxonomy)

\begin{tabular}{llllll}
\cline { 2 - 6 } Conditions & Remember & Apply & Analyze & Evaluate & Create \\
Real name & 2 & 3 & 1 & 29 & 14 \\
Anonymous & 14 & 0 & 10 & 71 & 14 \\
\hline
\end{tabular}

\subsection{Patterns of responses}

Several themes emerged along with the content analysis of students' responses.

Responses in real name conditions were longer, more complete, and more detailed. When students interacted with "Apply" an "Create" questions, they usually constructed complete, longer sentences with detailed "Create" question, they usaly constucted " "Apply" question: "Based on your or "Apply" question: "Based on your ow experience, whether you agree with the autho or not? Why? Give an example?", most real- name responses made their opinions first then supported with reasoning or evidence:

I believe that a teacher's age may impact their relationship with technology in their classroom. In my experience, I have found that some older educators have he habit of teaching the same lessons the same wa the needs and strengths of the students in their class. More experienced educators have found teaching techniques that work for them and maybe hesitant to try new technologies in their lessons (Student 1). he same way every year, regardless of
I think that implementation is the biggest mistake that effects EDTECH in schools. ources to integrate technology, but for those that do, they usually do not know how to show teachers the correct way to use the products. Professional development is led by the producers of the technology which show educators how to use the equipment, but do not show them how to use the technology to assist students with different needs. Therefore, the technology is useful as it could be (Student 2).

I've seen this mistake in schools before Schools force their teachers to use the latest and greatest technology in their classrooms with little to no thought about how it will affect the students. The students are the ones being forced to adapt to the different technological tools rather than schools evaluating what the students actually need and coming up with solutions to fit that (Student 3 ).

Similarly, for the "Create" questions, responses with real names tended to be
complete sentences with comparatively complete sentences with comparatively
detailed explanations. For instance, for the question "Design a learning activity with at least one verb and one digital tool to each category of Bloom's taxonomy," some of the real-name responses were:

Students can use Voice Thread to talk about a topic or person that they learned about (Student 4).

Students can play a matching game such as clicking on a state when its name is prompted by the game (Student 5).

Students can comment on a discussion board or blog (about) what they remember bout a certain lesson (Student 6).

Students can create a Prezi that explains the cause of and predicts the future impacts of climate change (Student 7).

Students can analyze their classmates' work in a google doc and have a debate (Student 8).

Responses in anonymous conditions were shorter, more fragmental, and without details. Unlike responses in real name conditions, anonymous responses were usually short and even phrases rather than complete sentences. For instance, for the same question, "Design learning activity with at least one verb and one digital tool to each category of Bloom's taxonomy." some anonymous responses were:

Personal Google Site (Anonymous)

Animation creation (Anonymous)

The contrast between anonymous or realname responses could be vividly seen in the responses to the following questions "Sharing one example of technology integration during your placement." Students in real naring plame to in pregre it into instuction while and how to integrate it into instruction while anonymous responses mostly contained the names of the technologies only:

We used Nrich to work on angle familiarity (Student 8).

Nrich during math; Youtube video clip during ELA lesson (Student 11) jeopardy game (Anonymous) powerpoint ${ }^{\wedge}$ (Anonymous)

audio book (Anonymous)

doc cam use (Anonymous)

math games online (Anonymous)

In other circumstances, some anonymou responses only gave a score as their rating without any further comments, such as 95 or 
Responses in real name conditions were formal and polite. Students tended to word their responses politely and positively in real name conditions. Sometimes even when they wanted to point out the drawbacks, they used euphemistic expressions or concession clauses. For instance:

The virtual science lab made by PBS was extremely interactive and included a lot of information on acids and bases. However, I did not think it was the most user friendly website. As a teacher going through the virtual lab, I even found it little confusing and tough. Tasks should be challenging for students, but I think be challen that this vitual ab was unclear in some of it's directions. A teacher could possibly print off specific directions for students that they could follow step by step while going through the lab which may end up being more beneficial. Furthermore, it was a little overwhelming because so much information about acids and bases was being given to sort of graphic organizer or note sheet that students could fill out as they went through the lab would be a good idea (Student 9).

Very engaging and founded in math concepts. Fairly accessible but require significant reading skills. The level of reading that is needed is usually found in older children who may not find the game very interesting (Student 6).

This is an engaging game that helps kid practice their math skills. It would be nice if it was more accessible for all learners, but it's not terrible overall (Student 11).

Responses in anonymous conditions were explicit and critical. In the meantime, students ended to post explicit in anonymous condition. For instance:
While it does challenge the students to think about math, it doesn't make it totally math oriented and the game can take away from the math side of it (Anonymous).

This game does a good job of showing off ratios. The students must already have knowledge on ratios to do this, though (Anonymous)

It is a fun game that will definitely engages all students. However, it might be a little confusing at first (Anonymous).

This game lagged a lot (Anonymous).

Fun but a little difficult to understand (Anonymous).

Responses in real name condition ontained many social messages, while responses in anonymous conditions did not. tespong in andenyms conditions did not. Among the incentere "great, [studenmented on each other, such as "great, [student name]." "very nice!" "great job!" "this is cool!" "cool!" However, those social messages did not lead to further conversations between students. While in anonymous conditions, only one post contained a social message "[student name] did a great job."

\subsection{Satisfaction and perception of} effectiveness

As shown in Figure 4, in general, most students in both Section A (77.78\%) and Section B (75\%) were satisfied with of Padlet in class. There was no significant difference of average satisfaction between the two sections $(t(15)=.39, p=n s)$. Only one student in Section B expressed dissatisfaction. However, this student regarded the use of the anonymous feature "Extremely effective." resulted from the anonymous feature.
Seven out of eight students in Section B some degree thought the anonymous feature was effective in allowing them to interact with others (Figure 5), and their evalution of effectiveness was highly corelated $(r=86, p$ $<.05$ ) with their self-reported frequency of the

uses of the anonymous feature.

In summary, the majority of students were satisfied with the use of Padlet and regarde the anonymous feature effective to some degree.

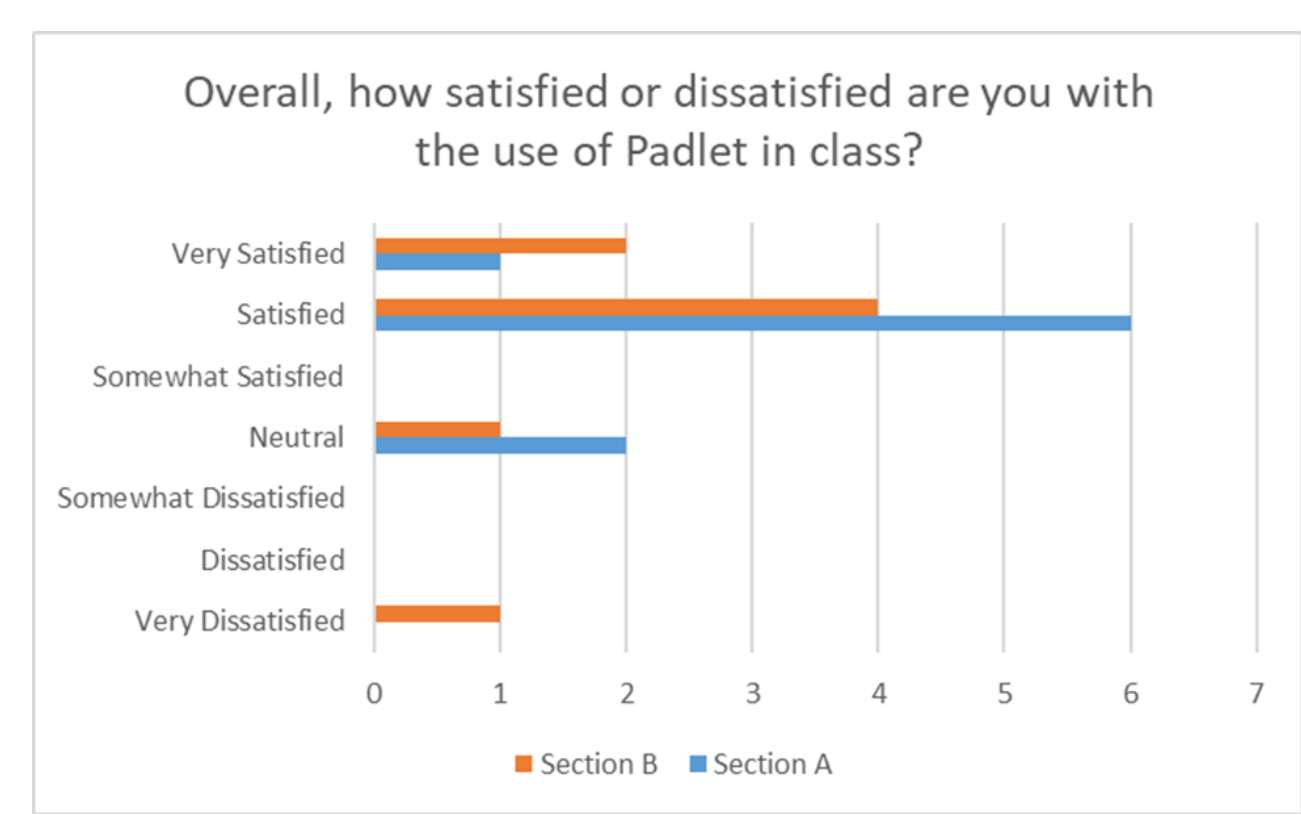

Figure 4. Satisfaction score of two sections

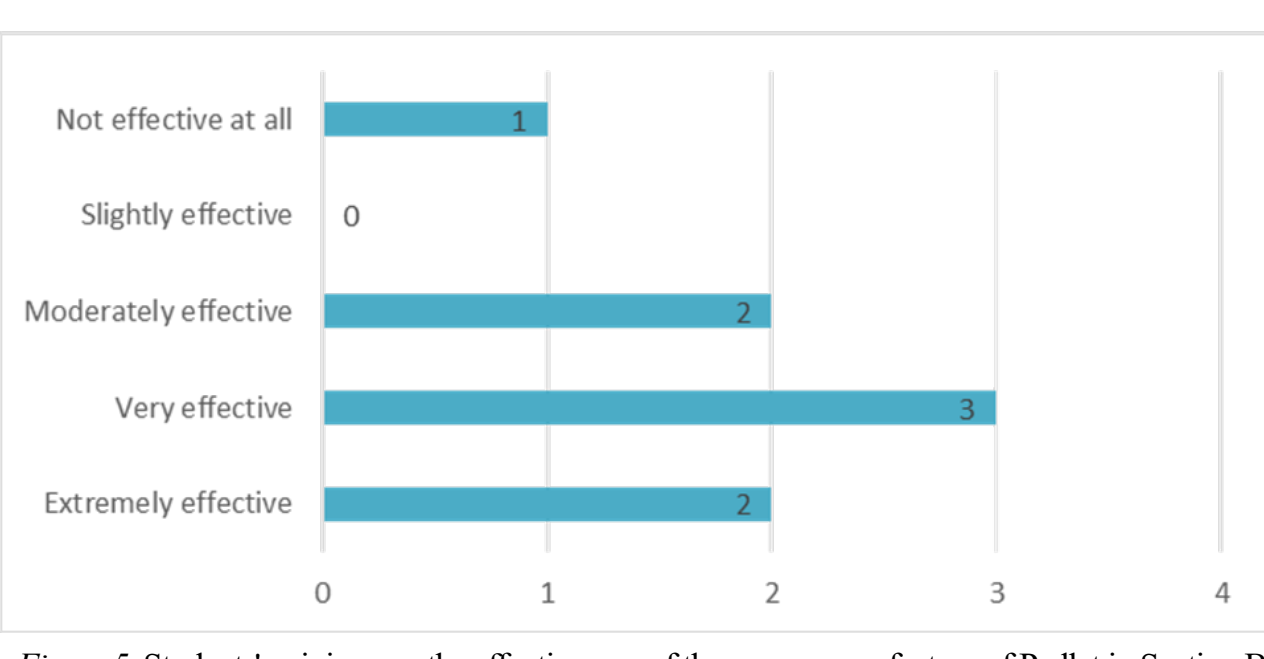

Figure 5. Students' opinions on the effectiveness of the anonymous feature of Padlet in Section B 


\section{Discussion}

\subsection{The influence of anonymity}

Based on the findings, although students in the control group interacted significantly more than students in the experimental group in the first week, the difference diminished and became insignificant in the remaining five weeks. In the experimental group, no students interacted anonymously in the first week. Towever, throughout six weeks, stud However throught six weeks, students condition than in real name conditions.

None of the students used the anonymous feature in the first week in Section B, which might be due to two reasons. First, in the firs class, when the instructors introduced student to the Padlet, they asked students to create an account. Although the instructors informed students that they could change their names in the setings page the seccoun post anonymously, students were busy playing with the novel platform and answering questions. Therefore, no students logged out to be anonymous or changed their usernames. Second, it was possible that initially, students thought identified interactions were importan for their participation grades. As Fassinger (1995) suggests, when students perceive that contributing to class will positively affect their cor Grades, they are mo likely to participate. When students were familiar with Padlet and ealized that the interactions were voluntary, they increasingly used the anonymous feature since the second week.

Being anonymous in the ARS, all students were able to contribute and share ideas freely and equally, regardless of the time and space limitations of oral discussion in a face-toface class. The discussion was less likely to in class leader who were active and brave enough to express their thoughts aloud (Uhari et al., 2003), or "Keeners" who had activity levels that were consistently higher than those of the other groups (Phirangee, Demmans Epp \& Hewitt, 2016). Even the "Lurkers" who were passivc 2016). Eve "Lussive recipients of the messages, rather than active contributors to discussions (Romiszowski \& Mason, 2004), could have their voice heard. Every student can be an active member of the learning community without concerns of any identified individual factors that might block him/her from interacting. Meanwhile, students also have equal chances to get contingent feedback from the instructor and peers, as most of the peer, as me selected by the instructors. At the same time, in the anonymous condition, the instructo would be less likely to provide feedback about self as a person, which was considered the least effective feedback type by Hattie and Timperley (2007). Thus, it might, to some extent, improve the overall effectiveness of feedback.

Moreover, although the content analysis showed that identified responses and anonymous responses differed in many ways, such as the length and wording, anonymous responses were not inferior in light of their accuracy or quality. Most anonymous responses were creative, and they only lacked details or examples. If the purpose of an ARS activity is to encourage interaction and quickly assess students' understanding, it would be expect long, formal-worded responses.

\subsection{Claiming the ownership of "Appy" and} "Create" questions

Results in the study suggested that students interacted significantly more with questions regarding "Apply" and "Create" in the real name condition condition. In previous studies especially with multiple choice questions or true-or-false questions, researchers find that students tend to compare their responses to their peers to see how well they are doing relative to their peers (Caldwell, 2007; Draper \& Brown, 2004; Simpson \& Oliver, 2007). Students who respond incorrectly may feel uncomfortable, particularly when most of the class is correct (Carnaghan \& Webb, 2007). Researchers also suggest that if cooperation and articulation of ideas are emphasized instead of getting a correct answer, students may feel less insecure about incorrect answers (Kay \& LeSage, 2009). In this case, both of the "Apply" and "Create" questions required some degree of originality and did not have only one accurate answer. "Apply" questions involved solving problems in new situations by applying acquired knowledge, facts, techniques, and rules. While "Create" facts, tech ines, and rules. While "Create" questions involved gencrating, planning (designing) or producing, or putting parts together to form a whole, with emphasis on creating a new meaning or structure (Bloom et al., 1956).

More interestingly, although some questions that were not coded as "Create" questions, students did contribute many responses through creating products using certain technologies. For instance, for the "Evaluate" question "Digital StorytellingPlease rate this tool and write a review about its strength, areas of improvement and accessibility." instead of evaluating the technology tool, many students posted the links to the digital storybooks that they created with real names. Similarly, there were also many cases when students posted screenshots or uploaded a document with real names to share what they created, no matter what the types of the questions really were.

Together it showed that these two types of questions enabled students to articulate their ideas without fear or concern of being wrong or negatively evaluated by others. In such situation, students wanted to claim ownership as they expended effort dealing with "Apply" and "Create" questions, and obviously, there is a lack of accountability (authorship) fo one's anonymous response (Barr, 2017). Thus, students might be more confident to use their real names to claim the ownership, present learner presence, and show competence. might be necessary to encourage learners to (they deal with questions regarding "Apply" or "Create."

\subsection{Preference of responding to "Evaluate"} questions anonymously

The only category with which student significantly preferred anonymous interaction ather than identified interaction was the "Evaluate" question, which involved presenting and defending opinions by making judgments about information, the validity of ideas, or quality of work based on a set of criteria (Bloom et al., 1956). This finding, to some extent, resonated with previous studies that found anonymity was effective in improving students' participation or interaction in conts with controveril topics or egarding the evaluation of peers, or critiques of others (Zhang \& Zhao, 2008)

Being anonymous, students expresse negative opinions freely, whereas using rea names, most of their responses were positive. It seems that being anonymous could help students to be free from being judged by others, and they would less likely be worried about being right or wrong. Anonymity encouraged their authentic cognitive reflection.

Therefore, this study suggested that the feature of ARS might be more useful for questions regarding "Evaluate," 
while the real name condition seemed preferable for questions regarding "Apply" or "Create." Therefore, it would make sense to recommend practitioners to make use of the anonymous feature of ARS in class to create a comfort zone to encourage students to interact in specific situations. Even withou ARS, practitioners could design instructional activities that enable students to interact in an anonymous environment. It should be noted that it might be preferable to provide students with the choice of being anonymous if time and resources permitted. As Yu and Liu (2009) suggested, flexible and versatile capabilites sggested, fl f computer and communication technologies should be ensured to allow individuals to be identified or only be identified via a nickname of their choice, so as to help eliminate feelings of embarrassment and uneasiness.

\subsection{Limitation}

One limitation of this study is the smal sample size, which might affect the reliability of the statistical analysis. Future studies are suggested to increase the sample size to 40 or higher. On the other hand, in our study, the small sample size allowed the instructors to spend more time and effort reviewing and spend mo time and effort review summarizing studer nded questions and providing appropriate feedback. When applying open-ended questions in a larger-sized class, careful, planned pedagogy is needed to ensure the feasibility and quality of the instructors' feedback, and its effectiveness should be examined.

Besides, the participants in the current study were pre-service teachers who were comparatively actively engaged in classroom interactions than other disciplines. Thus, it might be necessary to investigate the influence of anonymous ARS with students from other disciplines.

\subsection{Implications for future researc}

Despite the limitations, based on our findings, some suggestions were proposed fo effectively using ARS to facilitate learning.

Provide students with the choice of being anonymous, especially when the questions are vertical with absolute answers or belong to "Evaluate" questions that ask for students' judgment.

- Select ARS with which students could easily and quickly switch between anonymous and real name conditions

Inform students of the requirement of identified interactions in ARS and its relationship to their course grade stage, so as to encourage voluntary interactions.

- To encourage identified participation, use horizontal questions such as "Apply" or "Create" questions.

- To ensure anonymity, avoid walking around or standing behind the students while they are typing.

For anonymous responses, when it is no practical to provide feedback to each question, make a random selection to ensure equality.

For anonymous responses, avoid asking questions that would potentially revea students' identities, such as "who post this (wrong answer)?" Instead, encourage other students to further explain.

To make it more efficient to debrief openended ARS questions, pair students in groups before ARS discussion or assign facilitators to summarize responses.

Specify the objectives for open-ended questions, such as the length, required components. Depending on the objectives, shorter, concise responses might be even more preferred than complete and detailed responses in some circumstances, such as for brainstorm questions, warm-up questions, or to save Q-A time. For instance, the instructor could simply put "In a word or two, write a possible cause to this problem."

\section{Conclusion}

Our findings suggested that in a faceto-face class, when given the option, the anonymous feature of ARS was increasingly used by students in their interactions, and the average class interaction was improved. Meanwhile, the effect of the anonymous feature of ARS on students' interactions in class differed according to types of questions. The anonymous feature was more useful and effective when students interact with "Evaluate" questions. While for "Create" or "Apply" questions, students preferred real name interactions.

This study confirmed that the implementation of the anonymous feature can benefit inclusiveness by allowing every student equal opportunity to participate in interactions in a face-to-face class. Future research is needed to explore more specific strategies to guide future implementation of integrating it in class, such as what to ask in ARS discussions, how to facilitate interactions, and how to provide constructive feedback and debrief the discussion.

\section{Acknowledgment}

We gratefully acknowledge Dr. Nick Smith for his comments and support.

\section{Reference}

Barr, M. L. (2017). Encouraging college student active engagement in learning: Student response methods and anonymity. Journal of Computer Assisted Learning, $33,621-632$.

Beatty, I. D., Gerace, W. J., Leonard, W. J., Dufresne, R. J. (2006). Designing effective questions for classroom response system teaching. Am J Phys, 74, 31-39.

Black, P., \& Wiliam, D. (1998). Assessment and classroom learning. Assessment in Education: Principles Policy Pract 1998; 5 7-74.

Bloom, B. S., Engelhart, M. D., Furst, E. J., Hill, W. H., \& Krathwohl, D. R. (1956). Taxonomy of educational objectives: The classification of educational goals. Handbook I: Cognitive domain. New York: David McKay Company.

Boscardin, C., \& Penuel, W. (2012). Explorin Benefits of Audience-Response System on Learning: A Review of the Literature. Academic Psychiatry, 36(5), 401-47.

Caldwell, J. E. (2007). Clickers in the large classroom: Current research and bestpractice tips. Life Sciences Education, 6(1), 9-20.

Carnaghan, C., \& Webb, A. (2007). Investigating the effects of group response systems on student satisfaction, learning, and engagement in accounting education. Issues in Accounting Education, 22(3) 391-409.

Cohen, J. (1960). A coefficient of agreement for nominal scales. Educ Psychol Meas, $20,37-46$.

Coleman, L. H., Paternite, C. E., \& Sherman, R. C. (1999). A reexamination of deindividuation in synchronous computermediated communication. Computers i Human Behavior, 15(1), 51-65.

Draper, S. W., \& Brown, M. I. (2004) Increasing interactivity in lectures using an electronic voting system. Journal of 
Computer Assisted Learning, 20(2), 8194.

Fassinger, P. (1995). Understanding Classroom Interaction: Students' and Professors' Contributions to Students' Silence. The Journal of Higher Education, 66(1), 8296.

Han, J. H. (2014). Closing the Missing Links and Opening the Relationships among the Factors: A Literature Review on the Use of Clicker Technology Using the 3P Model. Educational Technology \& Society, 17(4), 150-168.

Han, J. H., \& Finkelstein, A. (2013). Understanding the effects of professors' pedagogical development with Clicker Assessment and Feedback technologies and the impact on students' engagement and learning in higher education. Computers \& Education, 65, 64-76.

Hattie, J., \& Timperley, H. (2007). The Power of Feedback. Review of Educational Research, 77(1), 81-112.

Hunsu, N. J., Adesope, A., \& Bayly, D. J. (2016). A meta-analysis of the effects of audience response systems (clicker-based technologies) on cognition and affect. Computers \& Education, 94, 102-119.

Jessup, L. M., Connolly, T., \& Gallagher, J. (1990). The effects of anonymity on group process in an idea generating task. MIS Quarterly, 14(3), 313-321.

Kay, R. H., \& LeSage, A. (2009). Examining the benefits and challenges of using audience response systems: A review of the literature. Computers \& Education, 53(3), 819-827.

Lapidot-Lefler, N., \& Barak, A. (2012). Effects of anonymity, invisibility, and lack of eye-contact on toxic online disinhibition. Computers in Human Behavior, 28(2), 434-443.

Phirangee, K., Demmans Epp, C., \& Hewitt, J. (2016). Exploring the Relationships between Facilitation Methods, Students' Sense of Community and Their Online
Behaviours. Online Learning Journal, special issue on Learning Analytics. 20. 10.24059/olj.v20i2.775.

Romiszowski, A., \& Mason, R. (2004). Computer-mediated communication. Handbook of Research on Educational Communications and Technology. 397432.

Simpson, V., \& Oliver, M. (2007). Electronic voting systems for lectures then and now: A comparison of research and practice. Australasian Journal of Educational Technology, 23(2), 187-208.

Stuart, S. A. J., Brown, M. I., \& Draper, S. W. (2004). Using an electronic voting system in logic lectures: One practitioner's application. Journal of Computer Assisted Learning, 20(2), 95-102.

Uhari, M., Renko, M., \& Soini, H. (2003). Experiences of using an interactive audience response system in lectures. BMC Med Educ, 3(12), 1-6.

Yu, F., \& Liu, Y. (2009). Creating a psychologically safe online space for a student-generated questions learning activity via different identity revelation modes. British Journal of Educational Technology, 40(6), 1109-1123.

Zhao, Y. (1996). The effects of anonymity on critical feedback in computer-mediated collaborative learning. Unpublished dissertation, University of Illinois at Urbana-Champaign.

Zhang, G. \& Zhao, Y. (2008). The Effects of Anonymity on Critical Feedback in a Teacher Preparation Program. In K. McFerrin, R. Weber, R. Carlsen \& D. Willis (Eds.), Proceedings of SITE 2008--Society for Information Technology $\&$ Teacher Education International Conference (pp. 3229-3234). Las Vegas, Nevada, USA: Association for the Advancement of Computing in Education (AACE). Retrieved October 4, 2018, from https://www.learntechlib.org/primary/ $\mathrm{p} / 27727 /$. 